\title{
GIS-based AHP analysis to recognize the COVID-19 concern zone in India
}

\author{
Prasoon Soni ${ }^{\circledR} \cdot$ Ithi Gupta $\cdot$ Pushpraj Singh • \\ Devendra Singh Porte $\cdot$ Dilip Kumar
}

Accepted: 3 February 2022 / Published online: 6 March 2022

(C) The Author(s), under exclusive licence to Springer Nature B.V. 2022

\begin{abstract}
This study was planned to identifying the Corona concerns zone during COVID-19 transmission in India. The death rate was very high due COVID-19 pandemic outbreaks which are one of the main reasons for impairment the countries, and it will takes several years for the re-establishment of the fundamental need to ensure the demand of public supply. Currently, like many countries around the world, India is also facing a drastic health crisis due to Corona virus disease. Analytical Hierarchy Process (AHP) and Geographical Information System (GIS) play important role in making the multi-criteria decisions and identifying the corona concern zone of a larger populated areas across the country in a single platform which can be further helpful for better control, planning, and management during several pandemic outbreaks. The present work is based on
\end{abstract}

\footnotetext{
P. Soni $(\bowtie) \cdot$ I. Gupta $\cdot$ P. Singh $\cdot$ D. S. Porte $\cdot$ D. Kumar Department of Rural Technology and Social Development, Guru Ghasidas University, Koni, Bilaspur, Chhattisgarh, India

e-mail: prasoonsoni05@gmail.com

I. Gupta

e-mail: guptaithi28@gmail.com

P. Singh

e-mail: contactprsingh@gmail.com

D. S. Porte

e-mail: portedevendra26@gmail.com

D. Kumar

e-mail: dilipkumar.ext15@yahoo.com
}

the AHP and GIS-assisted identification, analysis, and representation of the state-wise corona concern zone of India. Consequently, the current examination is essential to investigate the Corona concern zone in order to support the management and planning authority of India to improve their strategies in respect to reduce or check the health risk during the emergency of pandemic due to COVID-19. The present study indicated that the state-wise priority of corona concern zone recorded higher in state Maharashtra, Uttar Pradesh, and Kerala as compared to the other part of the India. Hence, GIS and AHP are the potential to identify, observe and analyze the COVID19 Concern Zone.

Keywords Analytical hierarchy process . Geographical information system · COVID-19 . Multi-criteria decision making

\section{Introduction}

The health care and safety is the primary criteria for the survival and sustaining the human's. COVID-19 transmission in India was examined in this work for identifying the corona concerns zone (CCZ). So, everyone should be aware about the basic health safety measures in order to control the health hazardous situations. In developing countries the death rate is very high due to several pandemic outbreaks which are one of the main reasons for impairment the countries 
and it takes several years for the re-establishment of the fundamental need to ensure the demand of public supply. Currently, like many countries around the world India is also facing a drastic health crisis due to corona virus disease therefore, this disease is considered as pandemic by World Health Organisation (WHO). Corona virus is an enormous family of infections which might cause sickness in human and animals. They generally cause a respiratory infections going from the normal virus to more serious sicknesses like Middle East Respiratory Syndrome (MERS) and Severe Acute Respirator Syndrome (SARS) and the most as of late found (COVID-19) causes irresistible illness (Chatterjee et al., 2020). In India The first case of COVID-19 was observed in the month of January 2020 (Kumar \& Sekhar Reddy, 2020). The COVID-19 has very high frequency to create a large scale outbreak in public health all over the world for human populations (Rai et al., 2020). A second wave was bigger than first wave, anticipated in March 2021. On the premise of mathematical simulation, a study was taken by the public authority of India on COVID-19 expressed that, this pandemic had crested in India and could handle by February 2021 (Ram et al., 2020).

For India, it is important to taken care of the circumstance, in light of the fact that the number of active cases was expanded step by step and nation surpassed Brazil as having the second-most position around the world. So India was started its vaccination program on January 2021 (Ram et al., 2020; Tiwari et al., 2020). At the beginning of inoculation program because of few might finish all periods of preliminary was slow however presently more than 80lakhs of portions each day will be given by Government of India (Hezam et al., 2021). Remote Sensing and GISbased planning can help in this issue to an extraordinary support for surveillance. Standard wise mapping were created utilizing Arc-GIS programming. The AHP with mix of GIS was observed to be exceptionally helpful for the reasonable site ID. Remote sensing and Geographical Information framework (GIS) can assume a persuasive part in supporting us just as policymakers for forming plans and approaches on the best way to handle this uncommon catastrophe by planning and breaking down the spread, impacts and most significant how to control (Only Possible by Vaccination) of this sickness all throughout the planet (Bhattarchajee \& Bhattacharjee, 2021). At the dynamic stage Analytical Hierarchy Process (AHP) and Multiple-measures dynamic (MCDA) was exceptionally accretive apparatus (Saaty, 1980). Insightful chain of importance model (AHP) and geographic data framework (GIS) were utilized in pack off investigations and exploration lodging and metropolitan development (Foroughi \& Rasol, 2016), the smallest expense way analysis (Effat \& Hassan, 2013), seismic risk affectability appraisal of the Ethiopian rift (Fentahun et al., 2021), Modeling metropolitan dynamics (Bharath et al., 2018), site reasonableness of restorative species (Piri et al., 2019), for strong waste management (Araiza Aguilar et al., 2018), for examination of groundwater potential storage (Ankana \& Dhanaraj, 2021), assessment of land suitability (Kamkar et al., 2014), reasonableness investigation for sitting sun based force plants (Hassaan et al., 2020), recognizable proof of groundwater potential zones (Verma \& Patel, 2021), appropriate locales for natural farming (Mishra et al., 2015) ID of flash flood hazard mapping (Elkhrachy, 2015), evaluation of sterile landfill sites (Hereher et al., 2020). The reactions are shaped with a couple insightful examination lattices, and an Analytical Hierarchy Process (AHP) approach is utilized figure the models/sub-rules loads (Rambo, 2021). A coordinated AHP investigation yield portrayal comprising of the level of hazard, grades, positioning, and significant reasons of hazard for model and sub-rules of this work is introduced. This danger appraisal study might assist with recognizing hazardous exercises so that individuals can pick other accessible alternatives (Garg \& Ganesh, 2020).

Analytical Hierarchy Process (AHP) and Geographical Information System (GIS) play important role for making multi-criteria decision and identifying the corona concern zone of a larger populated areas across the country in a single platform which can be further helpful for better control, planning and management during such pandemic outbreaks. The current COVID-19 pandemic is obviously a worldwide hazardous health condition. Henceforth, there is a need of examination the health emergency for the better implementations of security measure. The present work is based on the AHP and GIS assisted identification, analysis and representation of state wise corona concern zone of India. Consequently, the current examination is essential to investigate the Corona concern zone in order to support the management and planning authority of India to improve their 
strategies in respect to reduce or check the health risk during the emergency of pandemic due to COVID-19.

\section{Literature review}

India is anguish severely from COVID-19 disease. Social distancing and lockdown rules play major role for controlling community spared, on other hand the COVID-19 disease also affected the economy, human living and environment. Where a harmful impact was observed for the economy and human life, the environment got a constructive one (Ghosh et al., 2020a, 2020b). COVID-19 disease not only affected the India but also observed to the many region of the world from an urban and rural context. COVID-19 disease and environmental affect of climatic parameters was also reported in London to four other cities (Birmingham, Leeds, Manchester, and Sheffield) (Ghosh, et al., 2020a, 2020b).The United Nation's Sustainable Development Goals (SDGs) also facing lot of troubles for achieving SDGs and will be suffered in huge direct to attain their target by 2030 and collaborative support from all countries can only help in this time (Nundy et al., 2021).

Human-to-human transmissions have been depicted with incubation period between 2 and 10 days, facilitating its spread via droplets, contaminated hands or surfaces or wind. Respiratory infections can be transmitted through droplets of different sizes: when the droplets are $>5-10 \mu \mathrm{m}$ in diameter they are referred to as respiratory droplets, and when they are $<5 \mu \mathrm{m}$ in diameter, they are referred to as droplet nuclei. According to existing evidence, COVID-19 virus is primarily transmitted between people through respiratory droplets and contact path, these droplets land on substance and surfaces around the person when an infected person coughs or exhales, other people then catch COVID-19 by touching these substance or surfaces, then touching their eyes, nose or oral cavity. Droplet transmission happens when a person is in close contact in a meter with other person who has symptoms of respiratory infection like coughing or sneezing. Transmission may also occur through contaminants in the instant atmosphere around the infected person. Therefore, transmission of the COVID-19 virus can arise by direct communicate with infected people and indirect contact with surfaces in the immediate environment or with substance used on the contaminated person like stethoscope or thermometer. Then comes airborne transmission which is various from droplet transmission as it refers to the occurrence of microbes within droplet nuclei, which are $<5 \mu \mathrm{m}$ in diameter, can remain in the air for long duration and be transmitted to others. In the context of COVID-19, airborne transmission may be probable in specific situation and settings in which actions or support treatments that produce aerosols are performed that is tracheal intubation, bronchoscope, open suctioning, administration of nebulised treatment, manual ventilation before intubation, turning the patient to the prone position, disconnecting the patient from the ventilator, non-invasive positivepressure ventilation, tracheotomy, and cardiopulmonary resuscitation The major challenge in India's fight against COVID-19 is the population, with a population density that is almost 3 times that of China. The scenario is potentially worse in urban slums where the population density may exceed above 250,000/ $\mathrm{km}^{2}$, make social distancing impracticable. As several as 140 million people in India are migrant daily-wage workers; with burden of national lockdown, they are being forced to return back to their native villages without being able to abide by government advisories of social distancing. Unluckily, another major difficulty in India's fight against COVID-19 has been the attitude and action of some of the citizens; there have been infrequent reports of civilians hiding travel history in an attempt to break out quarantine and people contributing in otherwise forbidden massive religious meetings. Although the health care infrastructure has been immediately supported and nearly 2000 dedicated COVID-19 facilities have been amassed all over the nation over a limited period of time, the dearth of doctors cannot be made up overnight. India has just 0.8 doctors per 1000 population as against Italy's 4.1, China's 1.8, Spain's 4.1, Iran's 1.1 and the United States' 2.6. Additionally, the eastern states of West Bengal and Odisha have recently been hit by a super cyclone named Amphan that have wreaked havoc in the 2 states. People stranded homeless by the natural calamity have been rescued and placed in cyclone shelters where social distancing is almost impossible (WHO, 2020). Previous epidemics of many rising viral contaminations have characteristically resulted in poor obstetrical outcome including maternal morbidity and mortality, maternal-fatal transmission of the virus, and infections and death (The Lancet, 2020). 


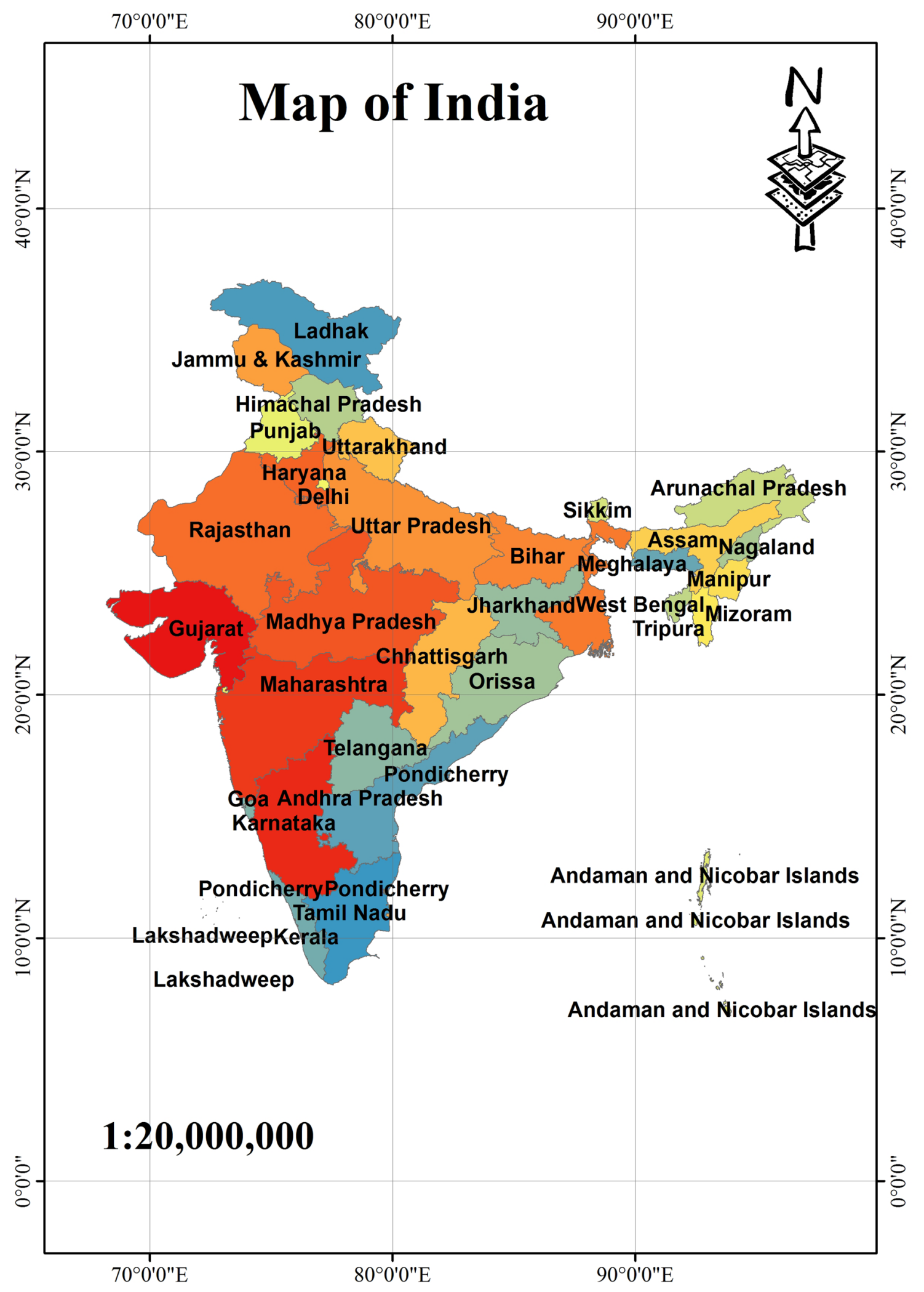


\Fig. 1 Map of study area

The combination of GIS with MCDA could make a contribution toward a current era for numerous migration evaluation and making plans (Rashid, 2019). Hence, the Analytical Hierarchy Process (AHP) and Geographical Information System (GIS) strategies have been proposed on the idea of MCDA methodology (Tripathi et al., 2021). A take a look at Suitability mapping of entrepreneurial possibilities on the micro- stage, that may bridge among an entrepreneur manufacturing hub and clients for empowering rural women for this multi-criteria decision analysis (MCDA) considered (Ahamed et al., 2020). The participation through wind power specialists with inside the AHP decision-making method for the utility scale wind farm suitability modelling and determined place represents the ability to yield an anticipated 29,000 MW of destiny utility-scale wind power capability map ability regions of groundwater have been determined that a location which has accomplished successive droughts over the past decades, inflicting the drying of maximum of the rivers with inside the place and use MCDA for exploring ground water exploitation processes (Al-Djazouli et al., 2021). Landslides are natural damaging phenomena that may motive top notch harm to belongings and lifestyles loss this parameter have been describe through MCDA very well (AlFanatseh, 2021). AHP is carried out SWOT evaluation and cause them to commensurable; thereby giving them the desired weight age with inside the strategic making plans method of the Community Based Tourism CBT (Balew et al., 2020). Account climatic parameters (wind pace and temperatures) and physical parameters (land cover, slopes, and distance from roads), our method is primarily based totally on remote sensing strategies of satellite data arrangement and Geographic Information Systems for spatial evaluation.

By method of a multi-criteria analysis a decision map of sites appropriate for destiny urban dynamics changed into carried out (Banik \& Mukhopadhyay, 2020). The temporal and seasonal water level fluctuation has been additionally use and evaluation, the use of analytical hierarchy method (AHP). Analysis of eve-teasing ability zones the use of geospatial technology and AHP in India (Bid \& Siddique, 2020). Analytic Hierarchy Process (AHP) have been additionally use to have a look at questionnaire primarily based totally survey (Dano, 2021). Adopting a vulnerability conceptual framework that conceptualizes susceptibility into three main components: exposure, sensitivity, and adaptive capability and the use of the analytical hierarchy process (Gathongo \& Tran, 2020). Analytic Hierarchy Process (AHP) primarily based totally opportunity method in which the network is positioned firmly on the centre (Priya \& Venkatesh, 2021). For analyzing various phenomena like slope, elevation, soil type, rainfall intensity, go with the drift accumulation, LULC, NDVI and distance from river and distance from road, MCDA have been very useful (Mukherjee \& Singh, 2020). In urban area to control the spread of COVID-19 virus the multi-criteria decision analysis can be used with inside the quantification of qualitative traits via its weighting. This makes it viable to categories consistent with their weight, the parameters selected for their effect on the susceptibility of the several urban sectors for the infection through SARS- CoV-2 virus (Kalla et al., 2021).

\section{Study area}

India is the leading nation of South Asia and the seventh-biggest country on the planet by region. The environment of India can comprehensively delegated Winter (December-February), Summer (March-June), South-west rainstorm season (June-September), Post storm season (October-November) (Islands, 2021). COVID-19 pandemic is the outbreak of a communicable disease caused by a recently discovered corona virus. The majority people contaminated with the COVID-19 virus will face mild to moderate respiratory sickness. According to Ministry of Health and Family Welfare the current corona case in India is 3, 89,583 with total discharge 3, 20, 28,825. However, India also starts free of charge vaccination programme and total vaccination 663037334 as 02 September 2021. The various lockdowns imposed by the government of India have also been employed in modelling and analyzing the proposed different modified models (Bedi et al., 2021).all the data in this study were collected from Indian health ministry from 7th of February 2021 (Fig. 1). 


\section{Methodology}

The present study was performed for India to evaluate the occurrence and distribution pattern of corona health crisis through the aid of AHP and GIS application. Based on AHP the entire study area were classified under three major cluster namely criteria, alternative and goal. The cluster criteria was further divided into five nodes viz., population, availability COVID-19 dedicated hospitals, active corona cases, death cases and vaccination status while all the Indian stats were categorised under four alternative clusters (Department of Science and Technology (n.d.)) (Fig. 2).

Analytic hierarchy process

The analytic hierarchy process (AHP), is a structured technique for organizing and analyzing multipart decisions, based on mathematics and psychology developed by Thomas L. Saaty in the 1970s. It represents a correct approach to quantifying the weights of conclusion
Fig. 2 Flowchart of the methodology adopted for the study

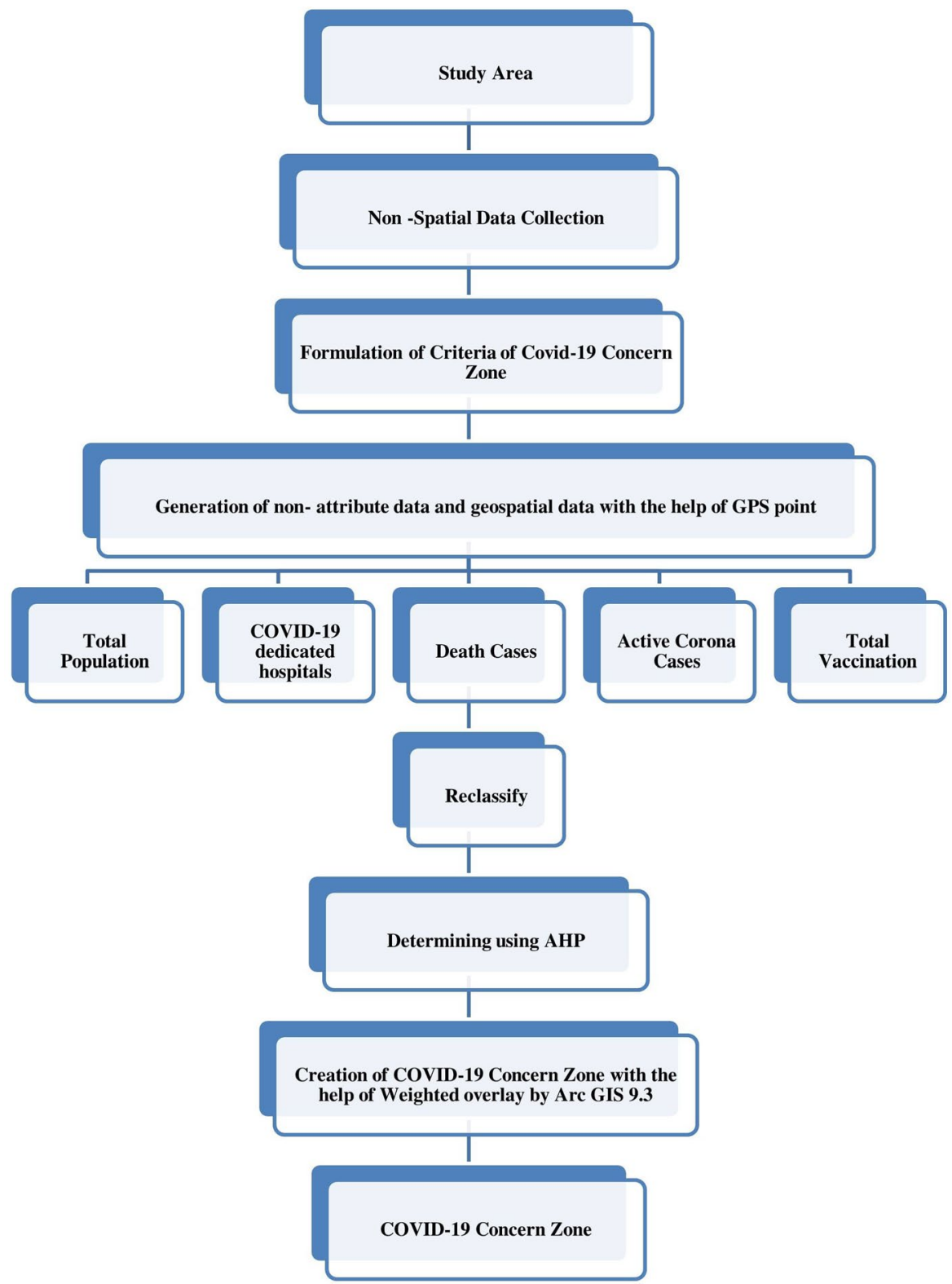


criteria. Individual experts' experiences are utilized to estimate the relative magnitudes of factors through pairwise comparisons. Each of the respondents compares the relative importance each pair of items using a specially designed questionnaire (Choice, 2013) (Table 1).

$C I=\frac{\lambda \max -n}{n-1}$

where $\mathrm{n}$ is the number of compared elements. $\lambda \max =$ Average of the values of weighted sum and priority. $\mathrm{CR}=$ Consistency ratio

$C R=C I / R I$

where $\mathrm{CR}=$ Consistency ratio. $\mathrm{CI}=$ Consistency Index.RI $=$ Random Index.

\section{Weighted Sum}

The weighted sum method comes together all the multiobjective functions into one scalar. In judgment theory, the weighted sum model (WSM), also called weighted linear combination (WLC) or simple additive weighting (SAW),is one of the best known and simplest multi-criteria decision analysis (MCDA)/multi-criteria decision making method for estimate a number of alternatives in terms of a number of decision criteria (Churchman \& Ackoff, 1954).

$(A i)^{W A M}=\sum_{j=1}^{n} \mathrm{Wj} \mathrm{Xij}$ where $X$ is the response variable and $W$ is the weights variable. The response variable and weights variable must have the same number of observations.

For this command, the weights are not normalized. However, at least one of the weights must be positive and none of the weights can be negative. Otherwise, an error message is reported.

\section{Kriging-in this study ordinary}

Kriging was used for study function interpolation tools in Arc GIS are referred to as deterministic interpolation methods because they are directly based on the surrounding measured values or on specified mathematical formulas that determine the smoothness of the resulting surface. (ESRI, 2011) The general formula for both interpolators is formed as a weighted sum of the data:

$\hat{z}\left(S_{0}\right)=+\sum_{i=1}^{n} \lambda i \mathrm{Z}\left(\mathbf{S}_{\mathbf{i}}\right)$

Where $\boldsymbol{Z}\left(s_{i}\right)=$ the measured value at the $i$ ts location $\lambda_{i}=$ an unknown weight for the measured value at the $i$ ts locations $s_{0}=$ the prediction location $N=$ the number of measured values
Table 1 The hierarchy proposed for decision to Identify COVID-19 concern zone

Saaty's pairwise comparison scale and consistency indices for a randomly generated matrix (Mu \& Rojas, 2017)

\begin{tabular}{|c|c|c|c|c|c|c|}
\hline \multirow{2}{*}{$\begin{array}{l}\text { Verbal judgment } \\
\text { Extremely important }\end{array}$} & & \multicolumn{5}{|l|}{$\begin{array}{l}\text { Numeric } \\
\text { value }\end{array}$} \\
\hline & & \multicolumn{5}{|l|}{9} \\
\hline & & \multicolumn{5}{|l|}{8} \\
\hline \multirow[t]{2}{*}{ Very Strongly more important } & & \multicolumn{5}{|l|}{7} \\
\hline & & \multicolumn{5}{|l|}{6} \\
\hline \multirow[t]{2}{*}{ Strongly more important } & & \multicolumn{5}{|l|}{5} \\
\hline & & \multicolumn{5}{|l|}{4} \\
\hline \multirow[t]{2}{*}{ Moderately more important } & & \multicolumn{5}{|l|}{3} \\
\hline & & \multicolumn{5}{|l|}{2} \\
\hline Equally important & & \multicolumn{5}{|l|}{1} \\
\hline \multicolumn{7}{|c|}{ Consistency indices for a randomly generated matrix } \\
\hline $\mathrm{N}$ & 1 & 2 & 3 & 4 & 5 & 6 \\
\hline RI & 0 & 0 & 0.58 & 0.9 & 1.12 & 1.24 \\
\hline
\end{tabular}




\section{Results \& discussions}

Pare wise compare matrix for consistency ratio

The pair wise compare matrix defines the relative priority among different criterion while the alternative helps to describe the goal of investigation. In current study the pair wise comparisons of hierarchy factors have been applied to find out the relative importance. The decision-makers examine the importance of pairs of linked factors in respect of their compare significance. Every value for a particular attribute was ultimately examined priority. Row and column defines the relative priority of different criterion (Table 2). Some other researches in COVID-19 had also been conducted with the help of AHP (Analytic hierarchy process) and GIS. Fever management in critically ill COVID-19 (Peluso et al., 2021). Some techniques could also be implemented in calculating the role and weight of different criteria/factors in spreading COVID-19 (Singh \& Avikal, 2020).

\section{COVID-19 concern zone of India}

In the present investigation the number of COVID19 dedicated hospitals in India were identified thus, the Indian state wise map for availability of COVID-19 dedicated hospitals clearly dipected that Uttar Pradesh and Karnataka state leads with maximum number COVID-19 dedicated hospital showing in red colour followerd by Andhra Pradesh and Rajasthan indicated by blue colour, the yellow colour indicator shows those states which were having moderate number hospitals for COVID-19 and grey colour in map indictaed those state where COVID19 dedicated hospital were found very less in number (Fig. 3A). Subsequently, The in the population map of India (Fig. 3B) the red colour representing the highly populated area located in Uttar Pradesh, the yellow colour indicates secondary high population distributed in Maharashtra, Bihar, West Bengal, and few areas of Rajasthan and Tamil Nadu. Likewise, the green colour directed the moderate population while the low populated areas are shown in grey coloured indicators. Furthermore, the map of death ratio shows that the maximum number of death was recorded in the populated areas of state Maharashtra shows very high number of death case due to COVID-19 pandemic indicated with red colour. However, the orange colour depicted the high death rate followed by light green i.e., moderate and dark green shows the minimum number of death cases by COVID-19 pandemic respectively (Fig. 3C).

In addition, COVID-19 vaccination programme in India, the map shows that the state Maharashtra is the leading state where the maximum attempt of vaccination programme, indicated by red colour in the map followed by blue coloured indicator, the second highest number of vaccinated state, green the moderate number vaccinated state and grey depicted minimum vaccinated states of India (Fig. 3D).

In addition, the positive COVID-19 cases in India the map shows that the state Maharashtra is the leading state where the maximum number of positive COVID-19 cases were recorded, indicated by red colour in the map followed by blue coloured indicator, the second highest number of positive COVID-19 cases, green the moderate number positive COVID-19 cases and grey depicted very less number of positive COVID-19 cases in India (Fig. 3E). Most of the corona cases have been observed from Maharashtra, Tamil Nadu, Delhi, and Gujarat (Chatterjee et al., 2020).

Table 2 Selected parameters and its priority weightage based on pair wise comparison

\begin{tabular}{llllll}
\hline Parameters & Total deaths & Number of hospitals & $\begin{array}{c}\text { Total Covid-19 cases } \\
\text { Total popu- } \\
\text { lation of } \\
\text { India }\end{array}$ & $\begin{array}{c}\text { Total Covid -19 } \\
\text { vaccination in } \\
\text { India }\end{array}$ \\
\hline Total deaths & 1 & 4 & 0.5 & 1 & 0.2 \\
Number of hospitals & 0.25 & 1 & 0.333333 & 0.25 & 0.2 \\
Total Covid-19 cases & 2 & 3.000003 & 1 & 2 & 0.5 \\
Total population of India & 1 & 4 & 0.5 & 1 & 1 \\
Total Covid -19 vaccination in India & 5 & 5 & 2 & 1 & 1 \\
\hline
\end{tabular}




\section{Covid-19 Concern Zone of india}

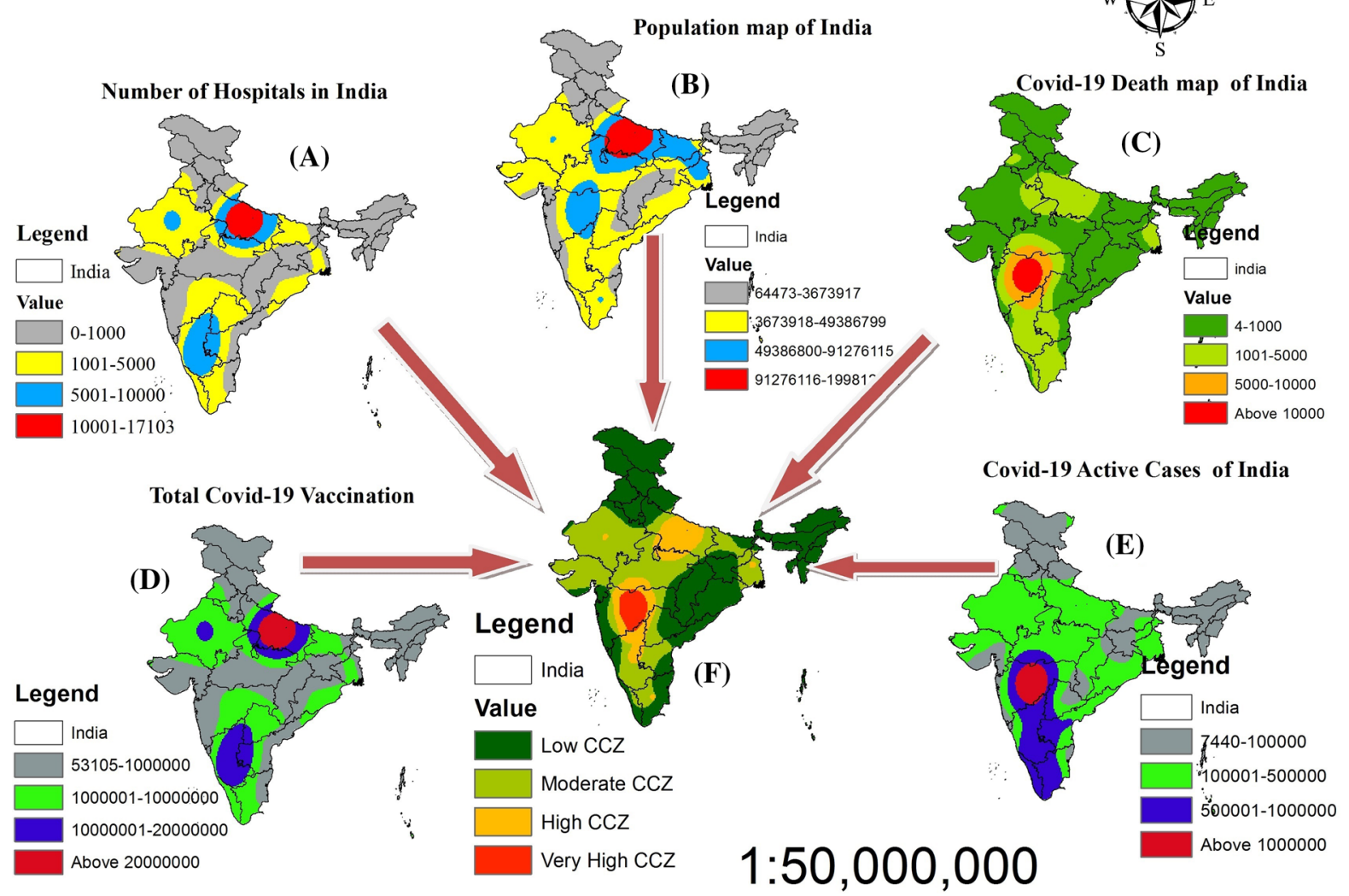

Fig. 3 A Number of Hospitals, B Population Map of India, C COVID-19 Death Map D COVID-19 Vaccination Map, E Map of total active COVID-19 cases and F COVID-19 concern zone

Sensitivity of crieria for COVID-19 concern zone

In present study the sensitivity of criteria of different region for COVID-19 concern zone the study area was divided into four group on the basis of statewise population in India in order to analyse the sensitivity of criteria. The study depicted that the COVID19 death criretia gettig three surprise point in whitch the priority of CCZ were altered (Fig. 4A). Looking towords the number of hospitals criteria in India having only one supriserd point (Fig. 4B) while possitive cases in India recognized with two surprised point where the prority was chnged (Fig. 4C). Finally, in the case of COVID-19 vaccination program in india which is highly concern area having no surprised point this indiactes that the current vaccination program should be continue as it is very essential to control the COVID-19 outbreak (Fig. 4D).
Overall statewise priority

In the presnt study the overall statewise priority was taken for the investigation and it revealed that the over all statewise priority of CCZ in which the state Maharashtra having highst priority of $\mathrm{CCZ}$ i.e., 0.078502 followed by Uttar Pradesh with 0.072447 and Kerala with 0.66072 repectively (Fig. 5).

Figure 5 show the overall priority of all states of India shows in this image and in Maharashtra state having highest priority of CCZ with 0.078592 which indicate that on the basis of expert opinion Maharashtra state have high chance to found COVID-19 concern zone according to the study. 


\section{Sensitivity of criteria for Covid-19 Concern Zone}

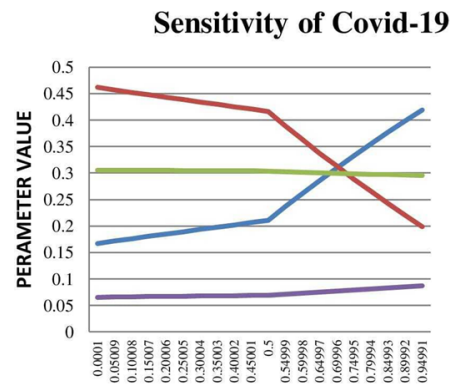

(A)

— Sensitivity for node Death state 1

- Sensitivity for node Death state2

- Sensitivity for node Death state3

- Sensitivity for node Death state4
Sensitivity of Covid-19 Cases

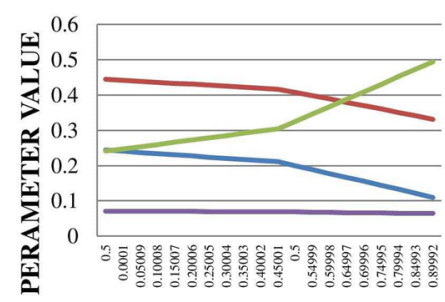

(C)

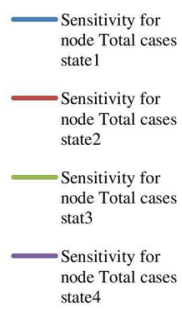

Sensitivity of Number of Hospital

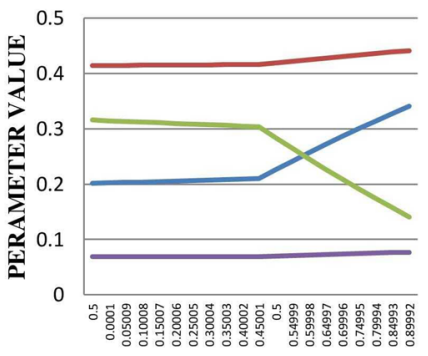

Sensitivity for node No. of hospital state1

Sensitivity for node No. of hospital state2

Sensitivity for node No. of hospital stat3

Fig. 4 Sensitivity analysis of criterion with four classified states

\section{Sensitivity of Covid-19 Vaccinations}

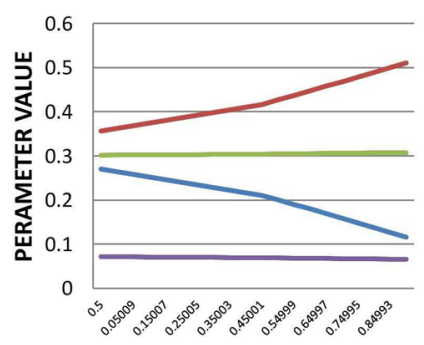

Sensitivity for node Total vaccination state1

Sensitivity for node Total vaccination state2

-Sensitivity for node Total vaccination stat3

Over All State wise priority for Covid-19 Concern Zone

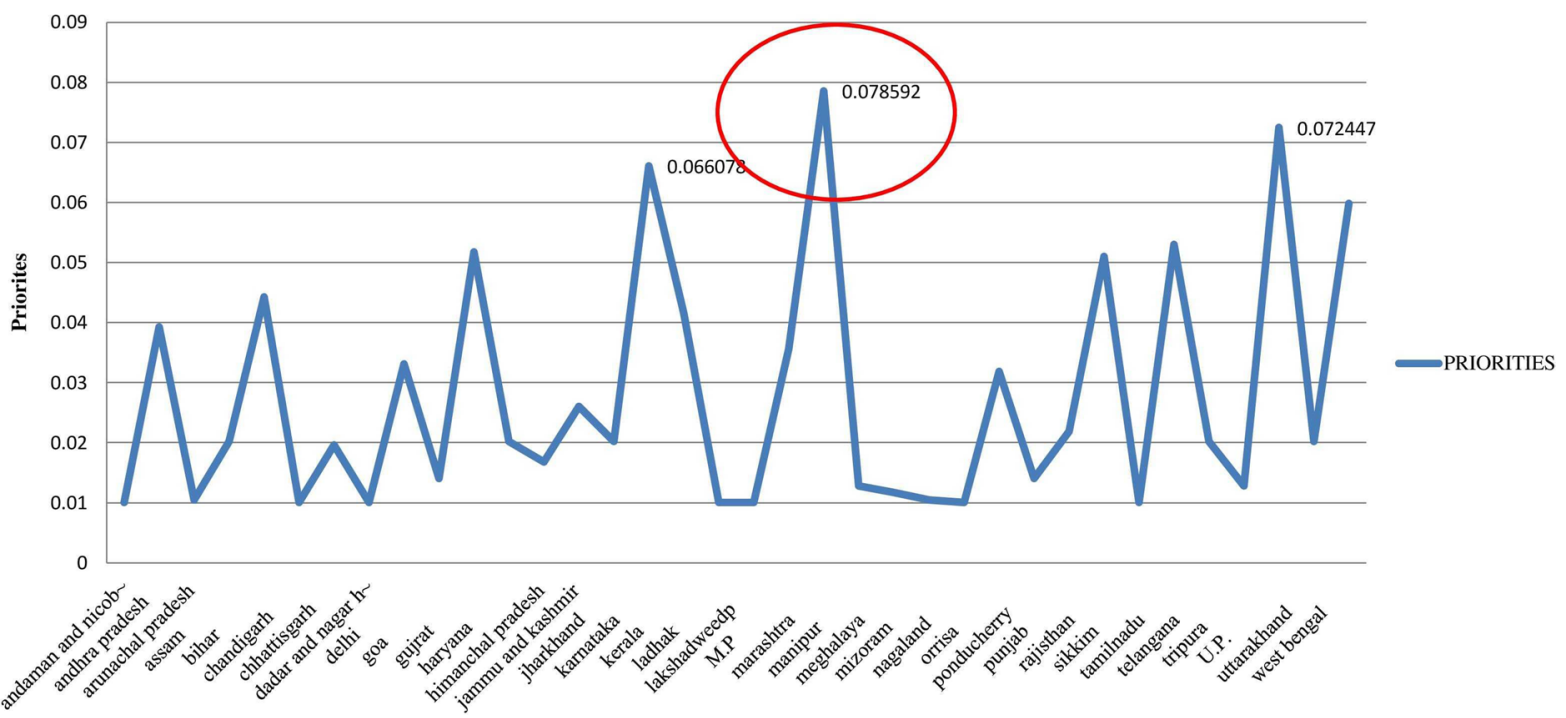

Fig. 5 Over all priority of all states of India 


\section{Conclusion}

The analysis of this study was mainly focused on identification of COVID-19 concern zone for decision making in India. AHP Matrix and GIS is used in the analysis in which five different criteria were considered the AHP and GIS tool of interpolation was found very useful for identification of COVID-19 Concern Zone. The AHP based identification for COVID-19 concern zone will very help full for policy-maker, decision-maker and research to know the $\mathrm{CCZ}$ in India. The final result may be accepted for the decision making process of the COVID-19 in the India, as it gives nearby in judgment the suitable areas. The results can be more polished by essentially analyzing the techniques used. The use of high aureate non spatial data will aid in analyzing finer areas. The identified zones have to be verified by various data provided by Press Information Bureau of India with other local parameters before the final implementation. Methods and models of predicting COVID-19 concern zone distribution of India is studied through data with high consistency that can impede a lot of time and cost and makes COVID-19 concern zone research cost-effective. GIS and AHP having great potential to help and support to identify, observe and analyze of COVID-19 Concern Zone.

Acknowledgements We acknowledge the remote sensing lab of Department of Rural Technology and Social Development, Guru Ghasidas Central University, Bilaspur, Chhattisgarh, India for providing all the necessary facilities for conducting this study.

Author contributions All authors have contributed equally to this work.

Funding The research was not supported by any funding.

Data availability The datasets during and/or analyzed during the current study available from the corresponding author on reasonable request.

\section{Declarations}

Conflict of interest On behalf of all authors, the corresponding author states that there is no conflict of interest.

Informed consent Informed consent was obtained from all individual participants included in the study.

Ethical approval On behalf of all authors, the corresponding author states that there is no conflict of interest and they have NO affiliations with or involvement in any organization or entity with any financial interest (such as sponsor or fund), or non-financial interest (such as personal or professional relationships, affiliations, knowledge, human participants or beliefs) in the subject matter or materials discussed in this manuscript.

\section{References}

Ahamed, T., Noguchi, R., Muhsin, N., Ayu Purnamasari, R., Islam, M. A., Tasnim, F., Islam, M. Z., Islam, M. F., \& Akmam, W. (2020). Sustainable agricultural development: A micro-level GIS-based study on women's perceptions of environmental protection and entrepreneurship in Japan and Bangladesh. GeoJournal (Vol. 5). Springer Netherlands. https://doi.org/10.1007/s10708-020-10169-5

Al-Djazouli, M. O., Elmorabiti, K., Rahimi, A., Amellah, O., \& Fadil, O. A. M. (2021). Delineating of groundwater potential zones based on remote sensing, GIS and analytical hierarchical process: A case of Waddai, Eastern Chad. GeoJournal, 86(4), 1881-1894. https://doi.org/10.1007/ s10708-020-10160-0

AlFanatseh, A. A. (2021). Land suitability analysis of urban development in the Aqaba area, Jordan, using a GIS-based analytic hierarchy process. GeoJournal. https://doi.org/10. 1007/s10708-021-10488-1

Ankana, \& Dhanaraj, G. (2021). Study of selected influential criteria on groundwater potential storage using geospatial technology and multi-criteria decision analysis (MCDA) approach: A case study. Egyptian Journal of Remote Sensing and Space Science. https://doi.org/10.1016/j.ejrs.2021. 06.004

Araiza Aguilar, J. A., Nájera Aguilar, H. A., Gutiérrez Hernandez, R. F., \& Rojas Valencia, M. N. (2018). Emplacement of solid waste management infrastructure for the Frailesca Region, Chiapas, México, using GIS tools. Egyptian Journal of Remote Sensing and Space Science, 21(3), 391399. https://doi.org/10.1016/j.ejrs.2018.01.004

Balew, A., Alemu, M., Leul, Y., \& Feye, T. (2020). Suitable landfill site selection using GIS-based multi-criteria decision analysis and evaluation in Robe town Ethiopia. Geojournal. https://doi.org/10.1007/s10708-020-10284-3

Banik, S., \& Mukhopadhyay, M. (2020). Model-based strategic planning for the development of community based tourism: A case study of Ayodhya Hills in West Bengal India. Geojournal. https://doi.org/10.1007/s10708-020-10314-0

Bedi, P., Dhiman, S., Gole, P., Gupta, N., \& Jindal, V. (2021). Prediction of COVID-19 trend in India and its four worst-affected states using modified SEIRD and LSTM models. SN Computer Science. https://doi.org/10.1007/ s42979-021-00598-5

Bharath, H. A., Chandan, M. C., Vinay, S., \& Ramachandra, T. V. (2018). Modelling urban dynamics in rapidly urbanising Indian cities. Egyptian Journal of Remote Sensing and Space Science, 21(3), 201-210. https://doi.org/10.1016/j. ejrs.2017.08.002

Bhattarchajee, T., \& Bhattacharjee, I. (2021). A review: How space technology can help in COVID-19 pandemic (with reference to Remote Sensing and GIS). Journal of Remote Sensing \& GIS, 10(3), 1-3. https://www. 
longdom.org/open-access/a-review-how-space-techn ology-can-help-in-covid19-pandemic-with-reference-toremote-sensing-and-gis.pdf

Bid, S., \& Siddique, G. (2020). Water-level fluctuation (WLF) of Panchet dam in India and assessment of its human risk using AHP method. GeoJournal. https://doi. org/10.1007/s10708-020-10266-5

Chatterjee, P., Anand, T., Singh, K. J., Rasaily, R., Singh, R., Das, S., Singh, H., Praharaj, I., Gangakhedkar, R. R., Bhargava, B., \& Panda, S. (2020). Healthcare workers \& SARS-CoV-2 infection in India: A case-control investigation in the time of COVID-19. 151(5): 459. https:// doi.org/10.4103/ijmr.IJMR

Choice, E. (2013). Analytic hierarchy process. Multi-Criteria Decision Analysis: Methods and Software. https://doi. org/10.1002/9781118644898.ch2

Churchman, C. W., \& Ackoff, R. L. (1954). An approximate measure of value. Journal of the Operations Research Society of America, 2(2), 172-187. https://doi.org/10. 1287/opre.2.2.172

Dano, U. L. (2021). An AHP-based assessment of flood triggering factors to enhance resiliency in Dammam Saudi Arabia. Geojournal. https://doi.org/10.1007/ s10708-020-10363-5

Department of Science and Technology. (n.d.). Indian supermodel for Covid-19 pandemic. O(0).

Effat, H. A., \& Hassan, O. A. (2013). Designing and evaluation of three alternatives highway routes using the analytical hierarchy process and the least-cost path analysis, application in Sinai Peninsula Egypt. Egyptian Journal of Remote Sensing and Space Science, 16(2), 141-151. https://doi.org/10.1016/j.ejrs.2013.08.001

Elkhrachy, I. (2015). Flash flood hazard mapping using satellite images and GIS tools: A case study of Najran City, Kingdom of Saudi Arabia (KSA). Egyptian Journal of Remote Sensing and Space Science, 18(2), 261-278. https://doi.org/10.1016/j.ejrs.2015.06.007

ESRI. (2011). How Kriging works. Resource Center, 1-7.

Fentahun, T. M., Bagyaraj, M., Melesse, M. A., \& Korme, T. (2021). Seismic hazard sensitivity assessment in the Ethiopian Rift, using an integrated approach of AHP and DInSAR methods. Egyptian Journal of Remote Sensing and Space Science. https://doi.org/10.1016/j. ejrs.2021.05.001

Foroughi, S., \& Rasol, M. A. (2016). Housing renovation priority in the fabric texture of the city using the analytic hierarchy model (AHP) and geographic information system (GIS): A case study of Zanjan City. Iran. Egyptian Journal of Remote Sensing and Space Science, 19(2), 323-332. https://doi.org/10.1016/j.ejrs.2016.05.001

Garg, A., \& Ganesh, T. (2020). An analytical hierarchy process approach for a Covid-19 risk assessment study amid the latest re-open and unlock phase in India. International Journal of the Analytic Hierarchy Process, 12(3), 565576. https://doi.org/10.1333/IJAHP.V12I3.814

Gathongo, N., \& Tran, L. (2020). Assessing social vulnerability of villages in Mt. Kasigau area, Kenya, using the analytical hierarchy process. GeoJournal, 85(4), 995-1007. https://doi.org/10.1007/s10708-019-10004-6

Ghosh, A., Nundy, S., Ghosh, S., \& Mallick, T. K. (2020a). Study of COVID-19 pandemic in London (UK) from urban context. Cities, 106(May), 102928. https://doi.org/ 10.1016/j.cities.2020.102928

Ghosh, A., Nundy, S., \& Mallick, T. K. (2020b). How India is dealing with COVID-19 pandemic. Sensors International, 1(July), 100021. https://doi.org/10.1016/j.sintl.2020. 100021

Hassaan, M. A., Hassan, A., \& Al-Dashti, H. (2020). GISbased suitability analysis for siting solar power plants in Kuwait. Egyptian Journal of Remote Sensing and Space Science. https://doi.org/10.1016/j.ejrs.2020.11.004

Hereher, M. E., Al-Awadhi, T., \& Mansour, S. A. (2020). Assessment of the optimized sanitary landfill sites in Muscat, Oman. Egyptian Journal of Remote Sensing and Space Science, 23(3), 355-362. https://doi.org/10.1016/j. ejrs.2019.08.001

Hezam, I. M., Nayeem, M. K., Foul, A., \& Alrasheedi, A. F. (2021). COVID-19 vaccine: A neutrosophic MCDM approach for determining the priority groups. Results in Physics, 20(2021), 103654.

Islands, L. (2021). 8/5/2021 Profile|National Portal of India. $1-4$.

Kalla, M. I., Lahmar, B., Geullouh, S., \& Kalla, M. (2021). Health geo-governance to assess the vulnerability of Batna, Algeria to COVID-19: The role of GIS in the fight against a pandemic. GeoJournal. https://doi.org/10.1007/ s10708-021-10449-8

Kamkar, B., Dorri, M. A., \& Da Silva, J. A. T. (2014). Assessment of land suitability and the possibility and performance of a canola (Brassica napus L.) —-soybean (Glycine $\max \mathrm{L}$.) rotation in four basins of Golestan province Iran. Egyptian Journal of Remote Sensing and Space Science, 17(1), 95-104. https://doi.org/10.1016/j.ejrs.2013.12.001

Kumar, S., \& Sekhar Reddy, D. (2020). Response to COVID19 pandemic in India: How can we strengthen our response? Indian Journal of Community Medicine. https:// doi.org/10.4103/ijcm.ijcm_653_20

Lancet, T. (2020). India under COVID-19 lockdown. The Lancet, 395(10233), 1315. https://doi.org/10.1016/S01406736(20)30938-7

Mishra, A. K., Deep, S., \& Choudhary, A. (2015). Identification of suitable sites for organic farming using AHP \& GIS. Egyptian Journal of Remote Sensing and Space Science, 18(2), 181-193. https://doi.org/10.1016/j.ejrs.2015. 06.005

Mu, E., \& Rojas, P. (2017). Practical decision maing process $(A H P)$ using the analytic hierarchy an introduction kto super decisions V2. Springer Nature. https://doi.org/10. 1007/978-3-319-33861-3

Mukherjee, F., \& Singh, D. (2020). Detecting flood prone areas in Harris County: A GIS based analysis. GeoJournal, 85(3), 647-663. https://doi.org/10.1007/ s10708-019-09984-2

Nundy, S., Ghosh, A., Mesloub, A., Albaqawy, G. A., \& Alnaim, M. M. (2021). Impact of COVID-19 pandemic on socio-economic, energy-environment and transport sector globally and sustainable development goal (SDG). Journal of Cleaner Production. https://doi.org/10.1016/j.jclep ro.2021.127705

Peluso, L., Montanaro, F., Izzi, A., Garufi, A., Djangang,N. N., Polain, A., Minini, A., Bogossian, E. G., Annoni, F., Spadaro, S., Creteur, J., \& Taccone, F.S. (2021). Fever 
management in critically ill COVID-19 patients: A retrospective analysis. Minerva anestesiologica. https:// doi.org/10.23736/S0375-9393.21.15711-6.

Piri, I., Moosavi, M., Taheri, A. Z., Alipur, H., Shojaei, S., \& Mousavi, S. A. (2019). The spatial assessment of suitable areas for medicinal species of Astragalus (Astragalus hypsogeton Bunge) using the analytic hierarchy process (AHP) and geographic information system (GIS). Egyptian Journal of Remote Sensing and Space Science, 22(2), 193-201. https://doi.org/10.1016/j.ejrs.2018.02.003

Priya, P., \& Venkatesh, A. (2021). Bringing communities at the centre of impact assessment of road projects: Integrating AHP with qualitative research. GeoJournal, 86(4), 16251637. https://doi.org/10.1007/s10708-020-10145-z

Rai, B., Shukla, A., \& Dwivedi, L. K. (2020). COVID-19 in India: Predictions, reproduction number and public health preparedness. MedRxiv. https://doi.org/10.1101/2020.04. 09.20059261

Ram, V. S., Babu, G. R., \& Prabhakaran, D. (2020). COVID19 pandemic in India. European Heart Journal, 41(40), 3874-3876. https://doi.org/10.1093/eurheartj/ehaa493

Rambo, O. (2021). Defining communities of interest: Political self-definition in Los Angeles County during the first California Citizen's Redistricting Commission. GeoJournal, 86(4), 1545-1587.

Rashid, M. F. A. (2019). Capabilities of a GIS-based multi-criteria decision analysis approach in modelling migration. GeoJournal, 84(2), 483-496. https://doi.org/10.1007/ s10708-018-9872-5

Saaty, T. L. (1980). Multicriteria decision making: The analytic hierarchy process: Planning, priority setting resource allocation. McGraw-Hill International Book Co.
Singh, R., \& Avikal, S. (2020). COVID-19: A decision-making approach for prioritization of preventive activities. International Journal of Healthcare Management, 13(3), 257262. https://doi.org/10.1080/20479700.2020.1782661

Tiwari, S., Kumar, S., \& Guleria, K. (2020). Outbreak trends of coronavirus disease-2019 in India: A prediction. Disaster Medicine and Public Health Preparedness. https://doi.org/ 10.1017/dmp.2020.115

Tripathi, A. K., Agrawal, S., \& Gupta, R. D. (2021). Comparison of GIS-based AHP and fuzzy AHP methods for hospital site selection: A case study for Prayagraj City India. Geojournal. https://doi.org/10.1007/s10708-021-10445-y

Verma, N., \& Patel, R. K. (2021). Delineation of groundwater potential zones in lower Rihand River Basin India using geospatial techniques and AHP. Egyptian Journal of Remote Sensing and Space Science. https://doi.org/10. 1016/j.ejrs.2021.03.005

WHO. (2020). World Health Organization FIFA/COVID-19 virtual press conference. 2(1), 5-7. https://www.who. int/docs/default-source/coronaviruse/ transcripts/whoaudio-emergencies-coronavirus-press-conference-full23mar2020.pdf?sfvrsn=846ecb41_4

Publisher's Note Springer Nature remains neutral with regard to jurisdictional claims in published maps and institutional affiliations. 